УДК 657.1

Д. С. Матусевич

Байкальский государственный университет, г. Иркутск, Российская Федерация

\title{
ОЦЕНКА ПРОДОВОЛЬСТВЕННОЙ БЕЗОПАСНОСТИ ПРЕДПРИЯТИЙ МЯСОПЕРЕРАБАТЫВАЮЩЕЙ ОТРАСЛИ (НА ПРИМЕРЕ ИРКУТСКОЙ ОБЛАСТИ)
}

\begin{abstract}
АНнотАция. В статье рассматривается подход к оценке продовольственной безопасности крупнейших мясоперерабатывающих предприятий Иркутской области посредством оценивания их ликвидности. Анализ ликвидности организации занимает центральное место в составе основных направлений изучения финансовой отчетности. Несмотря на то, что в целом методику анализа ликвидности можно считать сформировавшейся, необходимо учитывать специфику формирования отдельных статей баланса предприятий мясоперерабатывающей отрасли для интерпретации результатов проводимого исследования. Последовательно разбирается каждая группа показателей, изучаются позитивные и негативные факторы, влияющие на отдельные показатели, описывается их влияние на мясоперерабатывающую отрасль, а через нее - на состояние продовольственной безопасности Иркутской области. В целом, применение методики анализа ликвидности позволяет объективно рассмотреть современное положение дел в данной отрасли Иркутской области.

кЛЮчЕВЫЕ СЛОВА. Продовольственная безопасность; экономический анализ; мясоперерабатывающая отрасль Иркутской области.

ИНФОРМАЦИЯ О СТАТЬЕ. Дата поступления 6 апреля 2016 г.; дата принятия к печати 29 апреля 2016 г.; дата онлайн-размещения 25 июля 2016 г.
\end{abstract}

D. S. Matusevich Baikal State University, Irkutsk, Russian Federation

\section{ASSESSING FOOD SECURITY OF MEAT-PROCESSING COMPANIES (AS ILLUSTRATED BY IRKUTSK OBLAST)}

\begin{abstract}
The article considers an approach to assessing food security of major meat-processing companies in Irkutsk Oblast through assessing their liquidity. An analysis of a company's liquidity takes a central position among main directions of studying economic statements. Regardless of the fact that on the whole the methods of liquidity analysis can be considered as developed, it necessary to take into account the specificity of developing separate balance figures for companies of the meat-processing industry in order to interpret the results of the given investigation. The article carries out a step-by-step identification of every group of indicators, examines positive and negative factors that influence separate indicators, describes their impact on the meat processing industry and through it on the state of food security of Irkutsk Oblast. On the whole, using methods of the liquidity analysis allows to honestly consider the current state of affairs in this industry of Irkutsk Oblast.

KEYWORDS. Food security; economic analysis; meat-processing industry of Irkutsk Oblast.

ARTICLE INFO. Received April 6, 2016; accepted April 29, 2016; available online July 25, 2016.
\end{abstract}

Ведущее место в обеспечении продовольственного обеспечения страны занимает мясопродуктовый подкомплекс. На его долю приходится свыше трети производимой валовой продукции, основных фондов и трудовых ресурсов. Выбор именно этого подкомплекса для анализа проблемы продовольственной безопасности определяется большим социальным значением его конечной продукции [1-4].

(ㄷ) Д.С. Матусевич, 2016

\section{Baikal Research Journal}

электронный научный журнал Байкальского государственного университета 
Мясоперерабатывающая отрасль в Иркутской области укрупненно представлена одним свинокомплексом (СХПК «Усольский свинокомплекс») и несколькими мясоперерабатывающими комбинатами, практически не имеющими собственной сырьевой базы: ПАО «Мясокомбинат “Иркутский”», ЗАО «Мясоперерабатывающий комбинат “Ангарский” , $\mathrm{AO}$ «Усольские мясопродукты» ${ }^{1}$ (названия организаций приведены по данным электронных выписок Единого государственного реестра юридических лиц ${ }^{2}$.

Одной из тем анализа финансовой отчетности предприятий является оценка их платежеспособности и ликвидности. Общепринятая методика подразумевает группировку активов и пассивов организации на четыре группы $A 1, A 2, A 3, A 4$ и $\Pi 1$, $\Pi 2, \Pi 3, \Pi 4$ по степени убывания ликвидности и срочности оплаты соответственно. В этом же документе приводятся соотношения групп активов и пассивов, свидетельствующих о способности предприятия удовлетворять требования кредиторов в установленные сроки: $A 1>\Pi 1, A 2>\Pi 2, A 3>\Pi 3, A 4<\Pi 4$ [5-7].

$\mathrm{C}$ одной стороны, единая устоявшаяся методика позволяет проводить универсальный анализ ликвидности организации [6-8], с другой стороны, необходимо учитывать характер формирования групп активов и пассивов (табл. 1), а также современные условия, в которых действуют мясоперерабатывающие предприятия (табл. 2).

Таблица 1

Соотношение групп активов и пассивов

\begin{tabular}{|l|c|c|c|c|}
\hline \multicolumn{1}{|c|}{ Мясоперерабатывающее предприятие } & \multicolumn{3}{c|}{ Группы активов и пассивов } \\
\cline { 2 - 5 } & $A 1$ и П1 & $A 2$ и П2 & $A 3$ и П3 & $A 4$ и $\Pi 4$ \\
\hline ПАО «Мясокомбинат “Иркутский”» & $<>$ & $>$ & $>$ & $<$ \\
\hline ЗАО «Мясоперерабатывающий комбинат “Ангарский”» & $<$ & $<>$ & $>$ & $<$ \\
\hline АО «Усольские мясопродукты» & $<$ & $>$ & $>$ & $>$ \\
\hline СХПК «Усольский свинокомплекс» & $>$ & $>$ & $>$ & $<$ \\
\hline
\end{tabular}

Знак «<>» означает, что соотношение групп активов и пассивов принимает как значение « $<$ » (меньше), так и значение «>» (больше).

Источник: Федеральная служба государственной статистики : офиц. сайт. URL : http://www.gks. $\mathrm{ru} /$ accounting_report.

Рассмотрим генезис некоторых групп активов и пассивов, а также оценим влияние отдельных статей баланса на показатели ликвидности [8-10].

Группа $A 1$ - наиболее ликвидные активы, представленные денежными средствами. При исследовании этой группы активов следует учесть, что производственный цикл мясоперерабатывающего предприятия в основном занимает 1-2 дня и готовая продукция сразу передается покупателям. Следовательно, остатки по кассе и расчетным счетам предприятий, как правило, содержат результаты продаж за несколько рабочих дней, а получаемые денежные средства тут же расходуются на текущие нужды предприятия. Таким образом, формально нарушается принцип мгновенной ликвидности $(A 1<\Pi 1)[6 ; 7]$.

Группа $\Pi 1-$ наиболее срочные пассивы, включающая в себя кредиторскую задолженность, где наибольшую долю занимает задолженность по поставкам мяса и, соответственно, таможенные платежи за поставки импортного мяса. С одной стороны, сотрудничество с производителями мяса носит долгосрочный харак-

\footnotetext{
${ }^{1}$ Деловое Приангарье. Товары и производители : стат. справ. Иркутск : Иркутскстат, 2013. 104 с.

${ }^{2}$ Сведения о государственной регистрации юридических лиц, индивидуальных предпринимателей, крестьянских (фермерских) хозяйств [Электронный ресурс] // Федеральная налоговая служба : офиц. сайт. URL : https://egrul.nalog.ru/.
}

\section{Baikal Research Journal}


тер, однако, с другой стороны, это создает трудности в планировании платежей поставщикам. Учитывая резкий рост стоимости валюты в конце 2014 г., в будущем следует ожидать либо увеличение данной группы пассивов, либо сокращение производственных запасов. Из соотношения групп П1 и П2 видно (см. табл. 2), что большая часть кредиторской задолженности перед производителями сырья оплачена кредитными средствами, что в свою очередь негативно влияет на себестоимость готовой продукции и рентабельность отрасли в Иркутской области (табл. 3) [1;6; 7].

Исходные данные для оценки ликвидности отдельных предприятий мясоперерабатывающий отрасли Иркутской области в 2011-2014 г2., тыс. p.

\begin{tabular}{|c|c|c|c|c|c|}
\hline \multirow{2}{*}{\multicolumn{2}{|c|}{$\begin{array}{c}\text { Мясоперерабатывающее } \\
\text { предприятие }\end{array}$}} & \multicolumn{4}{|c|}{ Показатель } \\
\hline & & \multirow{2}{*}{\begin{tabular}{|l|}
2011 \\
102572 \\
\end{tabular}} & \multirow{2}{*}{$\begin{array}{r}2012 \\
1924 \\
\end{array}$} & \multirow{2}{*}{$\begin{array}{r}2013 \\
6042 \\
\end{array}$} & \multirow{2}{*}{$\frac{2014}{20874}$} \\
\hline \multirow{8}{*}{$\begin{array}{l}\text { ПАО «Мясокомбинат } \\
\text { "Иркутский”» }\end{array}$} & $A 1$ & & & & \\
\hline & $\Pi 1$ & 59071 & 80535 & 123082 & 107845 \\
\hline & $A 2$ & 220844 & 397386 & 403813 & 418620 \\
\hline & $\Pi 2$ & 293857 & 164475 & 159268 & 162846 \\
\hline & $A 3$ & 397008 & 199149 & 215448 & 109705 \\
\hline & $\Pi 3$ & 20000 & 20000 & 20000 & 20000 \\
\hline & $A 4$ & 80134 & 68397 & 62344 & 77861 \\
\hline & $\Pi 4$ & 424218 & 398502 & 381936 & 313154 \\
\hline \multirow{8}{*}{$\begin{array}{l}\text { ЗАО «Мясоперераба- } \\
\text { тывающий комбинат } \\
\text { “Ангарский”" }\end{array}$} & $A 1$ & 35266 & 10167 & 43668 & 17291 \\
\hline & $\Pi 1$ & 67617 & 60646 & 56529 & 53920 \\
\hline & $A 2$ & 87773 & 92195 & 85584 & 82663 \\
\hline & $\Pi 2$ & 122106 & 141119 & 44809 & 111267 \\
\hline & $A 3$ & 230387 & 286120 & 224140 & 295490 \\
\hline & $\Pi 3$ & - & - & - & 425 \\
\hline & $A 4$ & 170781 & 186561 & 173710 & 187968 \\
\hline & $\Pi 4$ & 334278 & 373278 & 425764 & 417754 \\
\hline \multirow{8}{*}{$\begin{array}{l}\text { АО «Усольские мясо- } \\
\text { продукты» }\end{array}$} & $A 1$ & 230 & 110 & 1613 & ... \\
\hline & $\Pi 1$ & 13456 & 12341 & 33263 & $\ldots$ \\
\hline & $A 2$ & 5384 & 20597 & 24198 & ... \\
\hline & $\Pi 2$ & 13906 & 14045 & 19933 & ... \\
\hline & $A 3$ & 15283 & 13543 & 31285 & ... \\
\hline & $\Pi 3$ & 11 & 33 & 28948 & ... \\
\hline & $A 4$ & 20505 & 19551 & 44830 & $\cdots$ \\
\hline & $\Pi 4$ & 14826 & 18396 & 20282 & $\ldots$ \\
\hline \multirow{8}{*}{$\begin{array}{l}\text { СХПК «Усольский } \\
\text { свинокомплекс» }\end{array}$} & $A 1$ & 464302 & 786997 & 565792 & 943770 \\
\hline & $\Pi 1$ & 61157 & 96531 & 76380 & 121623 \\
\hline & $A 2$ & 123518 & 109796 & 77806 & 182833 \\
\hline & $\Pi 2$ & - & - & - & - \\
\hline & $A 3$ & 1181671 & 1281723 & 1798492 & 1704300 \\
\hline & $\Pi 3$ & - & - & - & - \\
\hline & $A 4$ & 665596 & 724078 & 901264 & 945202 \\
\hline & $\Pi 4$ & 2373930 & 3859263 & 3266974 & 3654482 \\
\hline
\end{tabular}

Источник: Федеральная служба государственной статистики : офиц. сайт. URL : http://www.gks. $\mathrm{ru} /$ accounting_report.

\section{Baikal Research Journal}


Таблица 3

Рентабельность основной деятельности с учетол кредитных средств, \%

\begin{tabular}{|c|c|c|c|c|}
\hline \multirow{2}{*}{$\begin{array}{l}\text { Мясоперерабатывающее } \\
\text { предприятие }\end{array}$} & \multirow[t]{2}{*}{ Год } & \multicolumn{3}{|c|}{ Рентабельность основной деятельности } \\
\hline & & $\begin{array}{l}\text { с учетом кредит- } \\
\text { ных средств }^{1}\end{array}$ & $\begin{array}{c}\text { без учета кредит- } \\
\text { ных средств }^{2}\end{array}$ & изменение \\
\hline \multirow[t]{4}{*}{ ПАО «Мясокомбинат “Иркутский” ” } & 2011 & 3,87 & 6,10 & 2,20 \\
\hline & 2012 & 1,97 & 4,00 & 2,05 \\
\hline & 2013 & $-0,06$ & 1,63 & 1,69 \\
\hline & 2014 & $-8,44$ & $-6,29$ & 2,15 \\
\hline \multirow{4}{*}{$\begin{array}{l}\text { ЗАО «Мясоперерабатывающий ком- } \\
\text { бинат “Ангарский”» }\end{array}$} & 2011 & 8,57 & 9,30 & 0,77 \\
\hline & 2012 & 9,34 & 10,10 & 0,76 \\
\hline & 2013 & 13,10 & 13,79 & 0,69 \\
\hline & 2014 & 3,29 & 3,60 & 0,31 \\
\hline \multirow[t]{4}{*}{ АО «Усольские мясопродукты» } & 2011 & $-6,31$ & $-6,01$ & 0,31 \\
\hline & 2012 & 3,15 & 3,25 & 0,10 \\
\hline & 2013 & 1,04 & 1,79 & 0,75 \\
\hline & 2014 & $\ldots$ & $\ldots$ & - \\
\hline
\end{tabular}

${ }^{1}$ Отношение строки 22003(4) «Прибыль (убыток) от продаж...» к строке 21203(4) «Себестоимость продаж ...» бухгалтерской отчетности.

${ }^{2}$ Отношение суммы строк 22003(4) «Прибыль (убыток) от продаж...» и 233303(4) «Проценты к уплате...» к строке 21203(4) «Себестоимость продаж...» бухгалтерской отчетности.

Группа $A 2$ - быстрореализуемые активы, в основном представленные дебиторской задолженностью [5-7]. Применительно к мясоперерабатывающим предприятиям можно выделить 3 причины, создающие данную задолженность:

1. Наличие собственных торговых фирм, выделенных как отдельные юридические лица. Однако в силу зависимости торговых фирм от головных предприятий, они могут быть использованы и как источник «живых» денег, предоставляя их головной организации в виде «аванса» под будущие поставки продукции, так и могут получать у головной организации отсрочку по оплате поставленной продукции.

2. Расчеты с крупными торговыми сетями Иркутской области, представленные в виде отсрочек по оплате, передачи продукции на реализацию, предоставления товарных кредитов.

3. Договоры на поставку продуктов питания в бюджетные учреждения Иркутской области (детские сады, школы, больницы и т. д.). Для этого в ассортименте предприятий вводятся порционные продукты для удобства приготовления еды в учреждениях.

Например, у ПАО «Мясокомбинат “Иркутский”» и АО «Усольские мясопродукты” доля дебиторской задолженности занимает значительную часть активов, что указывает на их «борьбу за долю на рынке любой ценой», т. е. предоставляют готовую продукцию крупным торговым сетям Иркутской области с отсрочкой оплаты (табл. 4). Соотнеся данные табл. 3 и 4 , можно сделать выводы, что подобная практика вредит данным предприятиям, но переломить сложившуюся тенденцию им будет крайне сложно.

Таблица 4

Соотношение дебиторской задолженности к валюте баланса в 2011-2014 22., \%

\begin{tabular}{|l|r|r|r|r|}
\hline \multicolumn{1}{|c|}{ Мясоперерабатывающее предприятие } & 2011 & 2012 & \multicolumn{1}{c|}{2013} & 2014 \\
\hline ПАО «Мясокомбинат “Иркутский”» & 28 & 60 & 59 & 67 \\
\hline ЗАО «Мясоперерабатывающий комбинат “Ангарский”» & 17 & 16 & 16 & 14 \\
\hline АО «Усольские мясопродукты» & 12 & 24 & 46 & $\ldots$ \\
\hline СХПК «Усольский свинокомплекс» & 5 & 4 & 2 & 5 \\
\hline
\end{tabular}

\section{Baikal Research Journal}


Группа П2 - краткосрочные обязательства, представленные краткосрочными кредитами. Как правило, данные кредиты берутся под закупку мяса и поэтому их наличие сильно коррелирует с активами группы $A 3$ (табл. 5).

Группа $A 3$ - медленнореализуемые активы, в основном состоящие из запасов сырья (мяса, оболочки, пищевых добавок). Для мясоперерабатывающих предприятий данная группа является наиболее ценной, так как запасы замороженного мяса позволяют обеспечивать бесперебойный выпуск готовой продукции в условиях длительных по времени поставок, эпидемической ситуаций у поставщиков мяса, колебания курсов валют и, с недавних пор, экономических санкций. Отметим, что рассматриваемые предприятия активно наращивают запасы, зачастую на кредитные средства, а также наблюдается их инвестиционная активность, отраженная в статье «Долгосрочные финансовые вложения», выраженные либо в строительстве новых объектов (цехов, складов, объектов инфраструктуры) на предприятиях, либо в приобретении новых магазинов для собственных торговых сетей (см. табл. 5) [9; 10].

Таблица 5

Соотношение отдельных статей к валюте баланса в 2011-2014 22., \%

\begin{tabular}{|c|c|c|c|c|c|}
\hline $\begin{array}{c}\text { Мясоперерабатывающее } \\
\text { предприятие }\end{array}$ & Статьи баланса & 2011 & 2012 & 2013 & 2014 \\
\hline \multirow{3}{*}{$\begin{array}{l}\text { ПАО «Мясокомбинат } \\
\text { “Иркутский”» }\end{array}$} & Краткосрочные кредиты & 36,6 & 39,6 & 23,2 & 26,0 \\
\hline & Запасы & 33,1 & 28,5 & 29,9 & 15,9 \\
\hline & Долгосрочные финансовые вложения & 15,7 & 1,0 & 1,0 & 1,1 \\
\hline \multirow{3}{*}{$\begin{array}{l}\text { ЗАО «Мясоперерабатыва- } \\
\text { ющий комбинат “Ангар- } \\
\text { ский”" }\end{array}$} & Краткосрочные кредиты & 23,3 & 25,5 & 8,5 & 19,1 \\
\hline & Запасы & 42,6 & 48,2 & 52,6 & 46,4 \\
\hline & Долгосрочные финансовые вложения & 1,3 & 1,5 & 1,7 & 3,1 \\
\hline \multirow{3}{*}{$\begin{array}{l}\text { АО «Усольские мясопро- } \\
\text { дукты» }\end{array}$} & Краткосрочные кредиты & 31,6 & 35,7 & 49,0 & \\
\hline & Запасы & 25,7 & 19,6 & 30,7 & \\
\hline & Долгосрочные финансовые вложения & 11,1 & 10,3 & - & \\
\hline \multirow{3}{*}{$\begin{array}{l}\text { СХПК «Усольский свино- } \\
\text { комплекс» }\end{array}$} & Краткосрочные кредиты & - & - & - & \\
\hline & Запасы & 47,3 & 42,8 & 52,0 & 43,3 \\
\hline & Долгосрочные финансовые вложения & 1,2 & 1,4 & 1,8 & 1,8 \\
\hline
\end{tabular}

Группа $A 4$ - трудно реализуемые активы, представленные основными средствами предприятия. Положительным моментом при анализе данной группы активов является их практически постоянное увеличение, что свидетельствует о регулярной модернизации и перевооружении предприятий.

Таким образом, проведенный анализ ликвидности мясоперерабатывающих предприятий Иркутской области показал следующие тенденции в данной отрасли:

Нарушение коэффициента мгновенной ликвидности можно объяснить коротким производственным циклом и, как следствие, ежедневным поступлением выручки, расходуемой на текущие нужды (см. табл. 1-2).

Существенная доля дебиторской задолженности формируется за счет предоставления льгот по оплате крупным торговым сетям Иркутской области, что сужает мясоперерабатывающим предприятиям поле для финансового маневра (см. табл. 3-4).

Увеличение и поддержание значительных запасов сырья за счет кредитных средств с одной стороны смягчает риски дефицита сырья, с другой стороны увеличивает себестоимость продукции как напрямую, в виде уплаты банковских процентов, так и косвенно, в виде затрат на содержание холодильников (см. табл. 5).

Соответственно, из изложенного можно сделать вывод, что ключевыми проблемами в области продовольственной безопасности мясоперерабатывающих отрасли Иркутской области следует считать отсутствие собственных источников мяса и

\section{Baikal Research Journal}

электронный научный журнал Байкальского государственного университета 
попытки диктата крупных торговых сетей своих условий поставки готовой продукции. Все это требует от предприятий «заморозки» существенных финансовых средств на поддержание запасов сырья и обслуживание дебиторской задолженности и банковских кредитов $[1 ; 3 ; 4 ; 10]$.

\section{Список использованной литературы}

1. Иркутская область в XXI веке: проблемы и ресурсы развития / А. П. Киреенко, С. В. Чупров, Л. В. Санина [и др.]. - Иркутск : Изд-во БГУЭП, 2014. - 422 с.

2. Пожидаева Е. С. Проблема продовольственной безопасности в современных условиях (на примере мясопродуктового подкомплекса) / Е. С. Пожидаева // Россия и мировое сообщество в контексте посткризисного развития : материалы Междунар. науч. конф. Москва, 1-2 июня 2011 г. : в 5 ч. / под общ. ред. Ф. Л. Шарова. - М. : Междунар. ин-т экономики и права, 2011. - Ч. 4. - С. 54-60.

3. Шуплецов А. Ф. Роль ресурсного потенциала и предпринимательских структур муниципальных образований Иркутской области в эффективном развитии региональной экономики / А. Ф. Шуплецов, Е. С. Нечаева // Baikal Research Journal. - 2015. - T. 6, № 4. DOI : $10.17150 / 2411-6262.2015 .6(4) .9$.

4. Шуплецов А. Ф. Россия как полноправный участник Всемирной торговой организации : задачи и возможности аграрного сектора экономики / А. Ф. Шуплецов, Ю. А. Помулева, В. А. Колесник // Вестник Иркутского государственного технического университета. 2015. - № 7. - C. 209-214.

5. Баканов М. И. Теория экономического анализа : учебник / М. И. Баканов, М. В. Мельник, А. Д. Шеремет. - 5-е изд., перераб. и доп. - М. : Финансы и статистика, 2008. - 536 с.

6. Ковалев В. В. Анализ баланса, или Как понимать баланс / В. В. Ковалев, Вит. В. Ковалев. - М. : Проспект, 2014. - $784 \mathrm{c}$.

7. Шеремет А. Д. Анализ и диагностика финансово-хозяйственной деятельности предприятия / А. Д. Шеремет. - М. : Инфра-М, 2009. - 366 с.

8. Слободняк И. А. Необходимость учета различных аспектов деятельности предприятия при проведении анализа его финансового состояния / И. А. Слободняк // Современное состояние и перспективы развития бухгалтерского учета, экономического анализа и аудита : материалы Всерос. науч.-практ. конф. 22-23 апр. 2005 г. - Иркутск : Изд-во БГУэП, 2005. - C. $157-159$.

9. Слободняк И. А. Бухгалтерская управленческая отчетность как система учетно-аналитической информации о деятельности организации / И. А. Слободняк // Международный бухгалтерский учет. - 2011. - № 19. - С. 11-22.

10. Слободняк И. А. Информация бухгалтерского учета как необходимый ресурс оценки эффективности деятельности учреждения / И. А. Слободняк // Современное состояние и перспективы развития бухгалтерского учета, экономического анализа и аудита : материалы Междунар. науч.-практ. конф. Иркутск, 18 апр. 2014 г. / под ред. Е. М. Сорокиной. - Иркутск : Изд-во БГУЭП, 2014. - С. 176-183.

\section{References}

1. Kireenko A. P., Chuprov S. V., Sanina L. V. et al. Irkutskaya oblast'v XXI veke: problemy $i$ resursy razvitiya [Irkutsk region in the 21st century: problems and development resources]. Irkutsk, Baikal State University of Economics and Law Publ., 2014. 422 p.

2. Pozhidayeva E. S. Problem of food security in current environment (as illustrated by the meat-product sub-complex). In Sharov F. L. (ed.). Rossiya i mirovoe soobshchestvo v kontekste postkrizisnogo razvitiya. Materialy Mezhdunarodnoi nauchnoi konferentsii. Moskva, 1-2 iyunya $2011 \mathrm{~g}$. [Russia and the World Community in the context of post-crisis development. Materials of the Science International Conference. Moscow, June 1-2, 2011]. Moscow, International Institute of Economics and Law Publ., 2011, pr. 4, pp. 54-60. (In Russian).

3. Shupletsov A. F., Nechayeva E. S. Role of the resource potential and business structures of municipal entities of Irkutsk Oblast in effective development of regional economy. Baikal Research Journal, 2015, vol. 6, no. 4. DOI: 10.17150/2411-6262.2015.6(4).9. (In Russian).

4. Shupletsov A. F., Pomuleva Yu. A., Kolesnik V. A. Russia as a full member of the WTO: challenges and opportunities of agricultural sector. Vestnik Irkutskogo gosudarstven-

\section{Baikal Research Journal}


nogo tekhnicheskogo universiteta = Bulletin of Irkutsk State Technical University, 2015, no. 7, pp. 209-214. (In Russian).

5. Bakanov M. I., Melnik M. V., Sheremet A. D. Teoriya ekonomicheskogo analiza [Theory of economic analysis]. $5^{\text {th }}$ ed. Moscow, Finansy i statistika Publ., 2008. $536 \mathrm{p}$.

6. Kovalev V. V., Kovalev Vit. V. Analiz balansa, ili kak ponimat' balans [Balance analysis, or how to understand the balance]. Moscow, Prospekt Publ., 2014. 784 p.

7. Sheremet A. D. Analiz i diagnostika finansovo-khozyaistvennoi deyatel'nosti predpriyatiya [Analysis and diagnosis of company's financial and functions performance]. Moscow, Infra-M Publ., 2009. 366 p.

8. Slobodnyak I. A. Necessity of accounting by types of various aspects of a company's performance while making analysis of its financial state. Sovremennoe sostoyanie i perspektivy razvitiya bukhgalterskogo ucheta, ekonomicheskogo analiza i audita. Materialy Vserossiiskoi nauchno-prakticheskoi konferentsii. 22-23 aprelya 2005 g. [Today's State and Prospects of Developing Accounting, Economic Analysis and Auditing. Materials of All-Russian Research Conference. April 22-23, 2005]. Irkutsk, Baikal State University Economics and Law Publ., 2005, pp. 157-159. (In Russian).

9. Slobodnyak I. A. Accounting managerial statements as a system of accounting and analytical information about company's performance. Mezhdunarodnyi bukhgalterskii uchet = International Accounting, 2011, no. 19, pp. 11-22. (In Russian).

10. Slobodnyak I. A. Information of accounting as a necessary resource of assessing efficiency of a company's performance. In Sorokina E. M. (ed.). Sovremennoe sostoyanie i perspektivy razvitiya bukhgalterskogo ucheta, ekonomicheskogo analiza i audita. Materialy Mezhdunarodnoi nauchno-prakticheskoi konferentsii. 18 aprelya 2014 g. [Today's State and Prospects of Developing Accounting, Economic Analysis and Auditing. Materials of International Research Conference. April 18, 2014]. Irkutsk, Baikal State University Economics and Law Publ., 2014, pp. 176-183. (In Russian).

\section{Информация об авторе}

Матусевич Длитрий Сергеевич - аспирант, кафедра экономики предприятия и предпринимательской деятельности; старший преподаватель, кафедра информатики и кибернетики, Байкальский государственный университет, 664003, г. Иркутск, ул. Ленина, 11, e-mail:mds@isea.ru.

\section{Author}

Dmitry S. Matusevich - PhD Student, Chair of Business Economy and Entrepreneurial Activity, Senior Lecturer, Chair of Computer Science and Cybernetics, Baikal State University, 11 Lenin St., 664003, Irkutsk, Russian Federation; e-mail: mds@isea.ru.

\section{Библиографическое описание статьи}

Матусевич Д. С. Оценка продовольственной безопасности предприятий мясоперерабатывающей отрасли (на примере Иркутской области) / Д. С. Матусевич // Baikal Research Journal. — 2016. — T. 7, № 4. — DOI : 10.17150/2411-6262.2016.7(4).14.

\section{Reference to article}

Matusevich D. S. Assessing food security of meat-processing companies (as illustrated by Irkutsk Oblast). Baikal Research Journal, 2016, vol. 7, no. 4. DOI : 10.17150/24116262.2016.7(4).14. (In Russian).

\section{Baikal Research Journal}

